\title{
XLI. Osmotic pressure: its relation to the membrane, the solvent, and the solute
}

\section{Frank Tinker D.Sc.}

To cite this article: Frank Tinker D.Sc. (1917) XLI. Osmotic pressure: its relation to the membrane, the solvent, and the solute, Philosophical Magazine Series 6, 33:197, 428-450, DOI: $10.1080 / 14786440508635656$

To link to this article: http://dx.doi.org/10.1080/14786440508635656

册 Published online: 08 Apr 2009.

Submit your article to this journal $[\pi$

Џ Article views: 5

Q View related articles $₫$ 
in the crystalline state have a structure corresponding to a formula $\mathrm{M}_{1} \mathrm{O}_{2} \mathrm{M}_{2} \mathrm{O}_{2}$, which we might call the constitution formula of the solid state; but this constitution formula may be quite different from the chemical constitution formula of the substances, or from the constitution of the liquid, gaseous, or ionic form. Thus the chemical constitution of xanotime may be that of a phosphate, and zircon may have the chemical constitution of a silicate; but we must also be aware of the possibility that identity of crystal structure does not involve identity or similarity of chemical constitution. Thus, if we regard xenotime as a phosphate, we need not regard zircon as a silicate or rutile as a titanate.

In conclusion, I want to express my indebtedness to Mr. H. Schjelderup for bis valuable assistance during these researches. My thanks are also due to Miss Liv Gleditsch for making the models which are reproduced in this paper.

University of Christiania, January $1,1917$.

XLI. Osmotic Pressure: its Relation to the Membrane, the Solvent, and the Solute. By Frank Tinker, D.Sc.*

$\mathbf{I}^{\mathrm{T}}$

$\mathrm{T}$ is a noteworthy fact that whereas most of the kinetic explanations of the mechanism of osmotic pressure have focussed an almost exclusive attention on the solute, the thermody namic cycle by which the osmotic laws are derived is carried out with the solvent, and with no reference to the solute as distinct from the solution $\dagger$. For this reason it has come to be generally recognized, at least by those who during recent years have treated the subject thermodynamically, that the osmotic mechanism is to be explained ultimately in terms of the solvent rather than the solute; osmotic flow, for instance, takes place because the potential of the pure solvent is greater than the potential of the solvent inside the solution. Experiment also lends strong support to this view. With the exception that moisture travels across a semipermeable membrane in a much more condensed condition than vapour proper, the phenomenon of osmotic

* Communicated by Sir Oliver Lodge, F.R.S., being part of a Thesis approved for the Degree of Doctor of Science in the University of London.

+ I refer to the process in which the osmotic pressure is first obtained in terms of the vapour pressure by the formula $P=\frac{\mathrm{RT}}{\mathrm{V}} \log \frac{p}{p^{\prime}}$, and then afterwards in terms of the concentration by combining this formula with Raoult's law $\frac{p}{p^{\prime}}=\frac{\mathrm{N}+n}{\mathrm{~N}}$. 
flow is very similar to that of vapour flow; diffusion proceeds from pure solvent to solution because the pure solvent induces a greater pressure and concentration inside the membrane than the solution does *.

In the present paper the snbject of osmosis is developed quantitatively from the above basis; and the osmotic pressure connected with the conditions inside the pure solvent, the solution, and the membrane. But inasmuch as for this purpose the Dieterici equation of state is largely employed, it is to be noted at the outset that the results obtained by the application of this equation are only of value in so far as it represents accurately the conditions inside fluids. The equation in its various forms has, however, been applied to fluids with such a measure of success that the formulæ developed herein are in all probability at least approximately accurate + .

\section{Notation.}

Liquid pressure (i. e. pressure inside liquid) $\ldots \ldots \ldots \ldots \ldots$

Vapour pressure $\ldots \ldots \ldots \ldots \ldots \ldots \ldots \ldots \ldots \ldots \ldots \ldots, p$

Pressure inside semipermeable membrane $\ldots \ldots \ldots \ldots \ldots \rho$

Hydrostatic pressure $\ldots \ldots \ldots \ldots \ldots \ldots \ldots \ldots \ldots \ldots \ldots, \Pi$

Osmotic pressure $\ldots \ldots \ldots \ldots \ldots \ldots \ldots \ldots \ldots \ldots \ldots \ldots, P$

Malecular volume..................... $V$

Work done during evaporation of 1 mul. ijto vapoul phace proper........................ A

Work done during evaporation of $1 \mathrm{~mol}$, into semipermeable membrane .........................

Expansion on solution (per solute molecule dissal ved) .... Coeffieient of compressibility ................ $\beta$

Heat of dilution $\ldots \ldots \ldots \ldots \ldots \ldots \ldots \ldots, \ldots \ldots \ldots$

Number of molecules of solvent in solution............ N

Number of molecules of solute in solution $\ldots \ldots \ldots \ldots \ldots n$

In addition the suffix 1 is used for the solvent (e.g. $V_{2}=$ mol. vol. of pure solvent) and the suffix 2 for the solute.

Partial pressures, volumes, \&c. (in solution) are indicated by dashed symbols.

When it is necessary to consider the rolume as a function of the hydrostatic pressure, an additional suffix is used. Thus $V_{1(a)}$ represents the molecular volume of pure solvent under the atmospheric pressure $a$.

The Dieterici equations employed are:--

for the pressure in the interior of the liquid

$$
\pi(\mathrm{V}-b)=\mathrm{RT} \text {; }
$$

for the external vapour pressure

$$
p=\pi e^{-\frac{\mathrm{A}}{\mathrm{R}} \mathrm{T}}=\frac{\mathrm{RT}}{\mathrm{V}-b} e^{-\stackrel{A}{\mathrm{RT}} .}
$$

* Tinker, Proc. Roy. Soc. Contemporary number.

$f+$ For the fundamental ideas underlying the Dieterici equation and its application to the determination of the vapour pressures of binary nixtures, the reader is referred to a previous paper by the author. Phil. Mag. xxxii. Sept. 1916, p. 295.

Phil. Mag. S. 6. Vol. 33. No. 197. May 1917, 2 G 


\section{The Processes Operative during Solution.}

It is obvious that when two fiuids are mixed together without appreciable total volume change, each component of the mixture separates the molecules of the other component from one another. An immediate consequence of this fact is that the partial pressures and concentrations of the two components are less in the mixture than in the pure substances themselves ${ }^{*}$, and if either component is capable of "evaporating" from the mixture into another phase, its partial pressure in that phase is also reduced. It is thus not necessary to assume, as some have done $f$, that the lowering of the vapour pressure of the solvent by the process of solution is dne to solvation, or even to the blocking by the solute molecules of solvent molecules which would otherwise evaporate $f$. It is the reduction in the pressure and concentration of the solvent inside the solution which causes the lowering of the vapour pressure, whilst solvation and other solntion effects which al-o occur are the cause of abnormalities in the reduced vapour pressure rather than the primary cause of the reduction itself.

The present section is a development of the theory of fluid mixtures from the fundamentals of the kinetic theory. 'The treatment has heen made as broad and general as possible so that it can be extended to solutions of any strength. The only assumptions made are the following :-

(i.) The pressure of any component inside a fluid mixture is inversely proportional to the free space available to each molecule of that component, $i . e$. it is inversely proportional to the

$$
\text { ( } \frac{\text { total free space in a given vol. }}{\text { no. mols. of the component in the given vol. }} \text { ). }
$$

(ii.) The exact relationship between the partial pressure of the component and the free space available to its molecules is given by the equation,

partial pressure $\left(\frac{\text { total free space in given vol. }}{\text { no. of mols. of compt. in given vol. }}\right)=\mathrm{RT}$.

* The simplest and most obvious case is that of mixing two gases without total volume change. Thus, if one volume of gas $A$ at atmos. press. is nixed with 1 vol. gas $B$ also at atmos. press. to give 2 vols. of mixture also at atmos. press., the partial pressures of $A$ and $B$ are only half the pressures inside pure $A$ and $B$.

+ Poynting, Phil. Mlag. (5) xlii, p. 298 (1896); Callendar, Proc, Roy. Soc. A. xc. (1908); Dolezale1, Zeit. Fhys. (hem. 1xxxiii. p. 40 (1913), and other papers.

$\ddagger$ Lowry, Phil. Mag. (6) xiii. p. 552 (1897). 
It is to be noted also that these assumptions are only valid for the interior of the fluid * ; but it is immaterial whether the fluid be the solution itself, the vapour phase proper, the membrane or any other medium in contact with the solntion. To prevent the sibject from becoming unduly complicated, it is also assumed that neither the solvent nor the solute is either associated or dissociated, and that no solvates are formed.

\section{(a) The Partial Pressures of Solvent and Solute inside the Solution.}

Let $\mathrm{N}$ mols. of a solvent $\mathrm{X}$ having an internal fluid pressure $\pi_{1}$ be mixed with $n$ mols. of a solute $Y$ having a fluid pressure $\pi_{2}$ so as to give a mixture of $(\mathrm{N}+n)$ mols. having a total fluid pressure $\pi$. During the mixing, both of the constituents $\mathrm{X}$ and $\mathrm{Y}$ will expand into one another until the pressure throughout the mixture is uniform, $i . e$. until " the mean free spice $\mathrm{F}$ per inolecule of eithar kind" is the same for each molecule, whether of $\mathrm{X}$ or of $\mathrm{Y} \dagger$. Or, using an alternative phraseology, on mixing, the molecular volumes $V_{1}$ and $V_{2}$ of the pure solvent and solution both alter themselves in such a way that $\left(V_{1}-b_{1}\right)$ and $\left(V_{2}-b_{2}\right)$ readjust themselves to a common volume which can be represented either by $V_{1}^{\prime}-b_{1}$ or $V_{2}^{\prime}-b_{2}$, or by the letter $F$.

* This is, of course, one of the fundamental Dieterici essumptions. The Dieterici equation for the pressure in the interior of a pure fluid is $\pi(\mathrm{V}-b)=\mathrm{RT}$.

† For this phrase I am indebted to Prnf. A. W. Yorter, F.R.S. The conditions before and after mixing can be represented graphically, as below :-

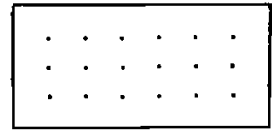

Nimole of pure solvent at press. $\pi_{\mathrm{I}}$.

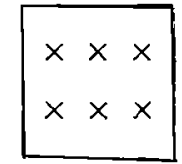

$n$ mols. of pure solute at press. $\pi_{2}$.

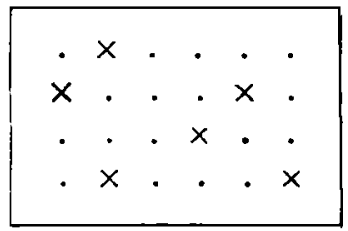

$(\mathrm{N}+n)$ mols, of solution at press. $\pi$.

Il ean free space $F$ the same for each molecule.

$2 \mathrm{G} 2$ 
We then have

Total free space in mixture

$$
=(\mathrm{N}+n) \mathrm{F}=(\mathrm{N}+n)\left(\mathrm{V}_{1}^{\prime}-b_{1}\right)=(\mathrm{N}+n)\left(\mathrm{V}_{2}^{\prime}-b_{2}\right) \text {. }
$$

Employing the equation postulated in the second assumption, we get immediately for the partial pressure $\pi_{1}{ }^{\prime}$ of the solvent inside the solution

$$
\pi_{1}{ }^{\prime} \frac{(\mathrm{N}+n)}{\mathrm{N}} \mathrm{F}=\mathrm{RT},
$$

and for the pressure $\pi_{1}$ inside the pure solvent

and hence

$$
m_{1}\left(\mathrm{~V}_{1}-b_{1}\right)=\mathrm{RT} \text {, }
$$

$$
\frac{\pi_{1}{ }^{\prime}}{\pi_{1}}=\frac{\mathrm{N}}{\mathrm{N}+n} \cdot \frac{\mathrm{V}_{1}-b_{1}}{\mathrm{~F}} \cdot \ldots . . .
$$

Similarly, for the partial pressure $\pi_{2}{ }^{\prime}$ of the solute inside the solution

$$
\frac{\pi_{2}{ }^{\prime}}{\pi_{2}}=\frac{n}{\mathrm{~N}+n} \cdot \frac{\mathrm{V}_{2}-b_{2}}{\mathrm{~F}^{\prime}} . \quad \text {. . . . }
$$

The equations [2] and [3] can be developed further by considering in detail the volume changes which take place on mixing.

Let the inerease in the total volume ${ }^{*}$ on mixing be ne (e can be looked on as the expansion of the total volume per molecule of solute added). We have

$$
\text { 'Total volume of solution }=\mathrm{NV}_{1}+n \mathrm{~V}_{2}+n \epsilon \text {, }
$$

Total free space in solution $=\mathrm{N}\left(\mathrm{V}_{1}-b_{1}\right)+n\left(\mathrm{~V}_{2}-b_{2}\right)+n \epsilon$.

But the total free spare in solution is also $=(\mathrm{N}+n) \mathrm{F}$. Hence

$$
\begin{aligned}
(\mathrm{N}+n) \mathbf{F} & =\mathrm{N}\left(\mathrm{V}_{1}-b_{1}\right)+n\left(\mathrm{~V}_{2}-b_{2}+\epsilon\right) \\
& =(\mathrm{N}+n)\left(\mathrm{V}_{1}-b_{1}\right)-n\left\{\left(\mathrm{~V}_{1}-b_{1}\right)-\left(\mathrm{V}_{2}-b_{2}+\epsilon\right)\right\} .
\end{aligned}
$$

Dividing throughout by $(\mathrm{N}+n)\left(\mathrm{V}_{1}-b_{1}\right)$, wo get

$$
\frac{\mathrm{F}}{\mathrm{V}_{1}-b_{1}}=1-\frac{n}{\mathrm{~N}+n}\left(1-\frac{\mathrm{V}_{2}-b_{2}+\epsilon}{\mathrm{V}_{1}-b_{1}}\right) \text {. . . }
$$

* I. e. the excess of the volume of the solution over the sum of the volumes of the two component.s. It is to be noted that $\epsilon$ varies with the pressure to which the solution is subjected; and that $V_{1}^{\prime}$ and $V_{2}^{\prime}$ are also variable with the pressure. But since in the present paper no pressures are ever put on the pure solvent or solute, $V_{1}$ and $V_{2}$ are regarded 28 being constant and equal to the molecular volumes at atmospherie pressure. 
Substituting in equation [2] we have

$$
\begin{aligned}
\frac{\pi_{1}}{\pi_{1}^{\prime}} & =\frac{\mathrm{N}+n}{\mathrm{~N}}\left\{1-\frac{n}{\mathrm{~N}+n}\left(1-\frac{\mathrm{V}_{2}-b_{2}+\epsilon}{\mathrm{V}_{1}-b_{1}}\right)\right\} \\
& =\frac{\mathrm{N}+n}{\mathrm{~N}} \frac{n}{\mathrm{~N}}\left(1-\frac{\mathrm{V}_{2}-b_{2}+\epsilon}{\mathrm{V}_{1}-b_{1}}\right) . . . .
\end{aligned}
$$

Similarly,

$$
\frac{\pi_{2}}{\pi_{2}^{\prime}}=\frac{N+n}{n}-\frac{N}{n}\left(1-\frac{V_{1}-b_{1}+\frac{n}{\mathrm{~N}} \epsilon}{\mathrm{V}_{2}-h_{2}}\right)
$$

Equations [2], [3], [4], [5], [6] are general, and hold whatever volume changes may take place in either the jartial volumes or the total volume.

Equations [2] and [3] show that the partial liquid pressures of the solvent and solute are determined partly by their respective molar fractions and partly by the changes in molecular volume which take plice on mixing.

The most important particular cise is the one in which we get the partial pressure of the solvent given by the relation

$$
\frac{\pi_{1}^{3}}{\pi_{1}}=\frac{\mathrm{N}}{\mathrm{N}+n}{ }^{*}
$$

It is erident from equation [2] that the relationship can hold only if $\mathrm{V}_{1}-b_{1}=\mathrm{F}=\mathrm{V}_{1}^{\prime}-b_{1}$, i. e. if $\mathrm{V}_{1}^{\prime}=\mathrm{V}_{1}$; in other words, the partial vapour pressure ratio $\frac{\pi_{1}^{\prime}}{\pi_{1}}$ for the solvent is equal to the molar fraction $\frac{\mathrm{N}}{\mathrm{N}+n}$ only when the molecular volume of the solvent undergoes no change by the process of solution. It can be shown, however, that all dilute solutions under normal conditions obey the relationship

$$
\frac{\pi_{1}^{\prime}}{\pi_{1}}=\frac{\mathrm{N}}{\mathrm{N}+n}
$$

more or less approximately $\dagger$. Consider, for instance, a litre

* As will be shown later, the simple osmotic laws for dilute solutions hold only when the above relationship holds.

+ It is important to note the limitation of "normal couditions." The partial pressures, both inside the solution and in the vapour phase proper, \&c., vary with the hydrostatic pressure placed on the solution. It will be shown subsequently that with ideal solutions, for instance, at osmotic equilibrium, $\pi_{3}^{\prime}$ and $\pi_{1}$ are equal instead of $\pi_{1}$ being greater than $\pi_{1}{ }^{\prime}$ as under normal conditions. 
of any deci-normal aqueous solution *, and, as an extreme case let

We have

$$
\left(\mathrm{V}_{2}-b_{2}+\epsilon\right)=10\left(\mathrm{~V}_{1}-b_{1}\right) \quad\{e f . \text { equation }[5]\} .
$$

$$
\begin{gathered}
n=\frac{1}{10}, \quad \mathrm{~N}-55 \cdot 5, \quad \frac{n}{\mathrm{~N}}\left(1-\frac{\mathrm{V}_{2}-b_{2}+\epsilon}{\mathrm{V}_{1}-b_{1}}\right)=-\frac{1}{60} \text { approx } \\
\quad \text { and } \quad \frac{\mathrm{N}+n}{\mathrm{~N}}=1 \text { approx. }
\end{gathered}
$$

The error in counting $\frac{\pi_{1}^{\prime}}{\pi_{1}}=\frac{N}{N+n}$ is thus $\frac{1}{60}$ on unity, or less than 2 per cent. The magnitude of the error is evidently determined by the number of solute molecules added to the solvent. If not many are added, their influence on the mean free space $\mathrm{F}$ in the solution is overwhelmed by the influence of the solvent, so that the internal conditions inside the solvent remain more or less unchanged.

We must not, however, suppose that because the solvent undergoes no appreciable volume change in the case of dilute solutions, the solute also undergoes no volume change, and also that the total volume ehange is zero. Both these latter hypotheses are in contradiction both to theory and experiment $\dagger$. The solute, for instance, has to change its molecular volume in such a way that $\left(\mathrm{V}_{2}-b_{2}\right)$ alters itself to

$\left(\mathrm{V}_{2}^{\prime}-b_{2}\right)=\mathrm{F}=\left(\mathrm{V}_{1}^{\prime}-b_{1}\right)\left\{=\left(\mathrm{V}_{1}-b_{1}\right)\right.$ for dilute solutions $\}$, i. e. on adding the solute to the solvent, in the case of dilute solutions, the free space of the solute readjusts itself to that of the pure solvent; whence the molecular volume of the solute also alters from $V_{2}$ to $\left(V_{1}-b_{1}+b_{2}\right)$. In the same way it can be shown by developing the equation [4], that the total expansion $n \epsilon$ on mixing is given by the relation

$$
n \epsilon=n\left\{\left(\mathrm{~V}_{1}-b_{1}\right)-\left(\mathrm{V}_{2}-b_{2}\right)\right\}-(\mathrm{N}+n)\left(\mathrm{V}_{1}-\mathrm{V}_{1}{ }^{\prime}\right) \text {. [7] }
$$

The total volume change becomes zero in two cases only :

(a) when $\left(\mathrm{V}_{1}-b_{1}\right)=\left(\mathrm{V}_{2}-b_{2}\right)$ and $\mathrm{V}_{1}^{\prime}=\mathrm{V}_{1}$ simultaneously, $i$. $e$. when the original "free spaces" of pure solvent and solute are equal and undergo no volune change on mixing;

(b) when

$$
\begin{aligned}
& (\mathrm{N}+n))\left(\mathrm{V}_{1}-\mathrm{V}_{1}^{\prime}\right)=n\left\{\left(\mathrm{~V}_{1}-b_{1}\right)-\left(\mathrm{V}_{2}-b_{2}\right)\right\} \\
& \text { or } \quad \mathrm{V}_{1}-\mathrm{V}_{1}^{\prime}=\frac{n}{\mathrm{~N}} \frac{n}{+n}\left\{\left(\mathrm{~V}_{1}-b_{1}\right)-\left(\mathrm{V}_{2}-b_{2}\right)\right\} .
\end{aligned}
$$

- A solution is usually taken as dilute up to a strength of $\frac{5}{10}$.

$\dagger$ It is well know a that a slight total volume change on solution is the rule, eren with very dilute solutions. For a comprehensive et of determinetions see Cameron \& Robinson, Journ. Phys. Chem. xiv. p. 1 (1910). 
It is evident that either of these conditions will be satisfied but rarely. In the (atie of dilute solutions (in which $V_{1}^{\prime}=V_{1}$ ) equation [7] indicates that the total volume change

$$
n \epsilon=n\left\{\left(V_{1}-l_{1}\right)-\left(V_{2}-l_{2}\right)\right\} .
$$

There will thus be an expansion or contraction on mixing according as $\left(V_{1}-b_{1}\right)$ is greater or less than $\left(V_{2}-l_{2}\right)^{*}$.

\section{(b) The Partial Pressures of the Solvent and Solute in the Vapour Phase.}

By combining the Dieterici equation with the foregoing results we can arrive at the laws obeyed by the solvent and solute in any other phase with which the solution is in contact and into which either (or both) solvent or solute can diffuse. 'The equation connecting the pressure of the solvent and soluto in any phase with the pressure inside the solution can be written as

$$
l^{\prime}=\pi^{\prime} e^{-\frac{A^{\prime}}{\mathrm{R}^{\prime} \bar{T}},}
$$

where $p^{\prime}$ and $\pi^{\prime}$ are partial pressures in the phase and solution respectively, and $A^{\prime}$ is the work done in transferring a molecule from the solution to the phase in question.

We thins have for the partial pressure of the solvent $p_{1}{ }^{\prime}$ in any phase (say the vapour phase) $\dagger$

$\frac{p_{i}}{p_{1}}=\frac{\pi_{1} e^{2}-\frac{A_{1}}{R T}}{m_{1}{ }^{\prime} e^{-\frac{A_{1}}{\mathrm{RT}}}}=\frac{\pi_{1}}{\pi_{1}{ }^{\prime}} e^{\frac{\partial A}{\mathrm{R}^{\prime} \mathrm{I}}}=\left\{\frac{\mathrm{N}+u}{\mathrm{~N}}-\frac{n}{\mathrm{~N}}\left(1-\frac{\mathrm{V}_{2}-b_{2}+\epsilon}{V_{1}-b_{1}}\right)\right\} \cdot \frac{\partial \Delta_{1}}{\mathrm{RT}}$,

$\partial \Lambda_{1}$ being the excess work performed by "evaporating", one molecule of the solvent from the solution into the phase over the work performed when the solvent is "evaporated" from the pure solvent.

We can extend the applicability of equations [8] and [9] by first proving that $\partial A_{1}$ is approximately equal to the heat of dilution $Q$ of the solution.

Let the pure solvent and the solution be separated from one another by the phase in question $\dagger$. A molecule of solvent can be conveyed from the puse solvent to the

* In the absence of solvation and association and dissociation changes this deduction should be capuble of experimental test. The fact that physical factors only can cause total volume change invalidates many determinations of the formulæ of the "hydrates" formed during solution from the volume changes which take place on mixing.

+ It is immaterial what this phase is. It may be either a vacuum (the vapour phase proper), a colloidal membrane, or another liquid or oolid in which the solvent and solute are soluble. 
solution irreversibly, and without the performance of external work, in two ways:

(i.) It can be allowed to diffuse into the phase in question first, to thell expand inside the phase from the pressure $p_{1}$ to the pressure $p_{1}{ }^{\prime}$, and lastly allowed to diffuse from the phase into the solution. The total heat given out by this process is $\partial A_{1}+U$, where $U$ is the diminution in the internal energy of the solvent during the expansion from $p_{1}$ to $\mu_{1}^{\prime}$.

(ii.) It can be andled directly to the solution, with a total heat evolution $Q$, where $Q$ is the heat of dilution.

Hence, since the total heat effect is independent of the path traversed, we have $\partial A_{1}+U=Q$.

For the vapour phase proper, at any rate, we can neglect $U$ so that $\partial \mathrm{A}_{1}=\mathrm{Q}$ (approx.).

Equation [9] can thus also be written

$$
\frac{p_{1}}{p_{\mathrm{l}}^{\prime}}=\left\{\frac{\mathrm{N}+n}{\mathrm{~N}}-\frac{n}{\mathrm{~N}}\left(1-\frac{\mathrm{V}_{2}-l_{2}+\epsilon}{\mathrm{V}_{1}-l_{1}}\right)\right\} e^{\stackrel{\mathbf{R}}{\mathbf{R}}} .
$$

If the heat of dilution of the solution is small compared with RT (as it usually is) the equation becomes

$$
\frac{p_{1}}{p_{1}}=\left\{\frac{\mathrm{N}+n}{\mathrm{~N}}-\frac{n}{\mathrm{~N}}\left(1-\frac{\mathrm{V}_{2}-b_{2}+\epsilon}{\mathrm{V}_{1}-b_{1}}\right)\right\}\left(1+\frac{\mathrm{Q}}{\mathrm{RT}}\right) \text {. }
$$

Equation [10] and its approximate form (equation 11) are the general equations for the vapour pressure of a solution of any non-volatile solute at any concentratios, it being assumed that neither the solvent nor the solute is associated or dissociated.

For the dilute solution the equation becomes:

$$
\text { or } \quad \begin{aligned}
& \frac{p_{1}}{p_{\mathrm{l}}^{\prime}}=\frac{\mathrm{N}+n}{\mathrm{~N}}\left(1+\frac{\mathrm{Q}}{\mathrm{RT}}\right) \\
& \frac{p_{1}^{\prime}}{p_{1}^{\prime}}=\frac{\mathrm{N}}{\mathrm{N}+\mu}\left(1-\frac{\mathrm{Q}}{\mathrm{R} \mathrm{l}^{\prime}}\right) . . . .
\end{aligned}
$$

(c) Ideal and Ton-Ideal Solutions.

The ideal solution may be defined as one whose partial vapour pressure under ordinary conditions is given by the equation

$$
\frac{p_{1}^{\prime}}{p_{1}}=\frac{N}{N+\imath}+
$$

* Supr , the approxinate equation $\frac{\pi_{1}{ }^{\prime}}{\pi_{1}}=\frac{\mathrm{N}}{\mathrm{N}+n}$ given on p. 433.

† Cf. Willard Gibbs, 'Nature,' Jx. p. 46(1897); Van Laar, Zeit. Phys. Chem. xr. p. 457 (1894). 
For this relationship to hold it is evident from equation [9] that (i.) the heat of dilution of the solution must le zero, and (ii.) the partial pressure of the solvent inside the solution shall be given by the equation

$$
\frac{\pi_{1}^{\prime}}{\pi_{1}}=\frac{\mathrm{N}}{\mathrm{N}+n}
$$

The latter condition is only fulfilled if the solvent undergoes no volume change during the process of solution ( vide p. 433). As is shown on p. 433, dilute solutions in general satisfy the latter relationship. We must not, however, infer that all dilute solutions are ideal. Equation [12] shows that they are only ideal if they have no heat of dilution. In the case of dilute sulphuric acid solutions, for instance ( $Q$ being positive), the vapour pressures are abnormally low *, whilst dilute aqueous phenolic solutions have a partial water vapour pressure which is almost equal to that of pure water $\dagger$.

Conversely, we may define non-ideal solutirns as those which do not satisfy the relationship

$$
\frac{p_{1}^{\prime}}{p_{1}}=\frac{\mathrm{N}}{\mathrm{N}+n} \text {. }
$$

It is evident that departure from ideality in the cases we have been dealing with are caused by't:

(i.) Volume changes of the solvent during the process of solution; these volume changes are caused by the fact that the free space (and intrinsic pressure) of the pure solute is generally different from that of the pure solvent, so that the solvent has to accommodate itself to the solute when the two are mixed together; and

(ii.) Heat effects on dilution. The vapour pressure tends to be abnormally high or low according as the solution has a negative or positive heat of dilution.

The general equation for the vapour pressure of non-ideal solutions is $[10]$.

* Cf. the figures given by Regnault, Ann. C'lim. Phys. (3) xv. p. 179 (1845); Sorel, Zeit. angew. Chem. p. 272 (1889).

+ Schreinemakers, Proc. Roy. Soc. Amsterdam, vi 1. iii. pp. 1 \& 701.

$\ddagger I$. e. with solutions in which the solvent and solute are neither associated nor dissociated, and in which there are no solvates formed. Evidently tbese latter effects, if they are present, will cause still greater deviations from ideality. 
2. The Phenomena of Osmotic Flow.

Consider a semipermeable membrane having a thickness sufficiently great for it to be regarded as a separate phase in the osmotic system*. Let the pure solvent be on one side of the membrane and the solution on the other. The solvent tends to diffuse into the membrane from both the pure solvent and the solution; a pressure $\rho_{1}$ (say) tending to be generated within the membrane by the pure solvent and a pressure $\rho_{1}^{\prime}$ (say) by the solution. From equation [9] $\frac{\rho_{1}}{\rho_{1}{ }^{\prime}}$ is given by the equation

$\frac{\rho_{1}}{\rho_{1}{ }^{\prime}}=\frac{\pi_{1}}{\pi_{1}{ }^{\prime}} e^{\frac{\mathrm{B}_{1}{ }^{\prime}-\mathrm{B}_{1}}{{ }^{\prime} \mathrm{I}}}=\left\{\frac{\mathrm{N}+n}{\mathrm{~N}}-\frac{n}{\mathrm{~N}}\left(1-\frac{\mathrm{V}_{2}-b_{2}+\epsilon}{\mathrm{V}_{1}-b_{1}}\right) e^{\frac{\mathrm{a \textrm {B } _ { 1 }}}{\mathrm{R} \mathrm{I}}}\right\},[13]$

where $\partial B_{1}$ is the excess of the latent heat of vaporization of the solvent from the pure solvent into the membrane over the heat of vaporization of the solvent from the solution into the membrane $\dagger$.

It is evident that the solvent will flow from the pure solvent to the solution if the pressure $\rho_{1}$ generated in the membrane by the pure solvent is greater than the pressure $\rho_{1}^{\prime}$ generated in the membrane by the solvent which is in the solution.

That this will almost invariably be the case under normal conditions can be shown as follows. Developing equation [13] we get

$$
\begin{aligned}
\frac{\rho_{1}-\rho_{1}{ }^{\prime}}{\rho_{1}{ }^{\prime}} & =\left\{\frac{\mathrm{N}+n}{\mathrm{~N}}-\frac{n}{\mathrm{~N}}\left(1-\frac{\mathrm{V}_{2}-b_{2}+\epsilon}{V_{1}-b_{1}}\right)\right\} e^{\frac{\partial \mathbf{B}_{1}}{\mathrm{RT}}}-1 \\
& =\frac{n}{\mathrm{~N}}\left(\frac{V_{2}-b_{2}+\epsilon}{V_{2}-b_{1}}\right) e^{\frac{\partial \mathrm{B}_{1}}{\mathrm{RT}} \text { (approx.), . . . [ [14] }}
\end{aligned}
$$

since $e^{\frac{\partial B_{1}}{\mathrm{R}^{1}}}$ dues not usually differ very much from unity.

Now, in practice, $e^{\frac{\partial \mathrm{B}_{1}}{\mathrm{RT}}}$ is always positive, whether $\partial \mathrm{B}_{1}$ is positive or negative, for $\partial \mathrm{B}_{1}$, which is usually negligible, is of a much less order of magnitude than RT. Also $\left(\mathrm{V}_{2}-b_{2}+\epsilon\right)$ is positive, except in the unlikely case in which the total expansion $(\epsilon)$ per solute molecule dissolved is negative and actually greater than the free space $\left(V_{2}-b_{2}\right)$ of the solute itself. Hence $\rho_{1}-\rho_{1}{ }^{\prime}$ will almost invariably be positive, so

* 'The actual colloidal membranes satisfy this condition.

+ The heat evaporation into the membrane is obviously not the sane as that into the vapour jhase proper. It is clear, however, from the general nature of the proof on p. 435 that the equations for $\rho$ are sinuilar to those for $p$. 
that $\rho_{1}$ will be greater than $\rho_{1}{ }^{\prime}$. This explains why osmotic flow usually takes place from pure solvent to solution. The pure solvent generates a greater solvent pressure inside the membrane than the solution does.

We must not, however, suppose that the solvent of necessity always flows irom pure solvent to solution. It would flow the other way if for any reason the partial pressure* generated in either the inembrane or the vapour phase proper by the solution were greater than the pressure generated by the pure solvent itself. It is not unlikely that solutions of ordinary phenol, which apparently under certain conditions have a partial water vapour pressure greater than the vapour pressure of pure water itself $\dagger$, come under this category. Prof. Adrian Brown and the present, aluthor havo proved that the phenolic solutions in general are very alnormal in their osmotic behaviour $\ddagger$.

In this connexion it is also interesting to note the effect of compressing the solution whilst loaving the pure solvent under atmospheric conditions. It is evident that the shrinkage cansed by compression will tend to make $\epsilon$ negative, so that nltimately, by the application of a pressure great enough $\left(\mathrm{V}_{2}-l_{2}+\epsilon\right)$ will become negative. When this occurs $\rho_{1}$ wlll become liss than $\rho_{1}^{\prime}$ and the solvent will flow from the solution to the pure solvent. 'This is actually what happens when a pressure greater than its osmotic pressure is applied to the solution.

Let us now consider the causes for the abnormalities in the phenomena of osmotic flow ; and let us confine attention in the first place to the ease in which two dilute solutions of different solutes, having equal concentrations and under the same external lyydrostatic pressure, are on opposite sides of the membrane. If $\rho_{1}^{\prime}$ and $\rho_{1}{ }^{\prime \prime}$ are the solvant pressures generated in the membrane in each case we have from the equation $[12]$

$$
\frac{\rho_{1}{ }^{\prime}-\rho_{1}^{\prime \prime}}{\rho_{1}}=\frac{\mathrm{N}}{\mathrm{N}+n}\left(\frac{\mathrm{Q}^{\prime \prime}-\mathrm{Q}^{\prime}}{\mathrm{R}^{\prime} \mathrm{T}}\right), \quad \cdot \quad \cdot .
$$

where $Q^{\prime}$ and $Q^{\prime \prime}$ are the heats of dilution of the two solutions. Similarly, for the vapour pressures proper, we have

$$
\frac{p_{1}{ }^{\prime}-p_{1}^{\prime \prime}}{p_{1}}=\frac{N}{N+n}\left(\frac{Q^{\prime \prime}-Q^{\prime}}{R^{\prime} T^{\prime}}\right) . . .
$$

* I. e. "Partial pressure of the solvent."

† Schreinemaker's, loc. cit. p. 14 ifootnote).

$\ddagger$ Proc. Roy. Soc. B. Mxxix. p. 119 (1915). 
From equations [15] and [16] we can derive three possible cases :-

(i.) If both of the dilute solutions are ideal and have zero heat of dilution, then $\rho_{1}{ }^{\prime \prime}=\rho_{1}{ }^{\prime}$ and $p_{1}{ }^{\prime}=p_{1}{ }^{\prime \prime}$. Two ideal solutions of equal concentration are thus in osmotic equilibrium with one another, and there will be no osmotic flow from the one to the other.

(ii.) If one solution is ideal and the other is not, the system is not in equilibrium, although the concentrations of the $t$ wo solutions may be equal. The flow will be from the ideal solution to the non-ideal solution, according as to the heat of dilution of the non-ideal solution is positive or negative.

(iii.) If both solutions are non-ideal, osmotic equilibrium is possible only when the two heats of dilution are equal. In any other case osmotic flow will take place from the solution having the lesser heat dilution to the solution having the greater.

By virtue of the relationships which have been established in the foregoing pages between the heat of dilution and the heat of vaporization, either into the membrane or into the vapour phase proper, the above case of osmotic flow for non-ideal solutions can be elaborated in somewhat more detail.

Thus, since $Q=\partial A_{1}=\partial B_{1}$ (loc. cit. p. 12), we can write

$$
Q^{\prime \prime}-Q^{\prime}=A_{1}{ }^{\prime \prime}-A_{1}{ }^{\prime}=B_{1}{ }^{\prime \prime}-B_{1}{ }^{\prime} \text {. }
$$

Hence, we may also state that the osmotic flow will take place from the solution having the lower value of $A_{1}{ }^{\prime}$ to that having the higher value of $A_{1}{ }^{\prime}$. Since $A_{1}{ }^{\prime}$ is a function of the intrinsic pressure which increases with the latter ${ }^{*}$, and consequently also with the surlace-tension $t$, we arrive at the further result that the flow will take place from the solution having the lower intrinsic pressure and surfacetension to that having the higher intrinsic pressure and surface-tension. Herein comes the application of the "intrinsic pressure" and surlace-tension theory of osmosis which I. Traube has advocated so vigorously on empirical groundsf. The preceding analysis shows that the theory

* This is an immediate deduction from the Laplace theory of capillarity It is in agreement with experiment also, since liquids which have a high intrinsic pressure have nlso a large latent heal.. (Cf. W. C. McC. Lewis, Trans. Fara day Soc. A pril 1911.)

$+A$ liquid which has a high intrinsic pressure and latent heat has also a hig burface-tension.

+ Journ. l'hys. Chen. xiv. p. 452 (1910) and other papens. Traube bas correlated surface-tension, vapour pressure, intrinsic pressure, \&c., with their effect on osmotic flow. 
must be limited to the case in which two non-ideal dilute solutions of equal concentration are placed on opposite sides of the membrane. Subject to this limitation Traube's surface-tension theory will no doubt continue to be of great value, even as it has proved to be in the past. The scope of Traube's theory, limited as above, would apparently be extensive*, for most actual solutions are more or less nonideal.

We can now sketch briefly the general theory of osmotic flow. It is evident that if two solutions (each under the same hydrostatic pressure) are on opposite sides of a membrane, the solvent will flow from the one which generates the greater presure $\dagger$ inside the membrane, $i$.e. from the one which has also the greater partial (solvent) vapour pressure. Now, the pressure generated by each solution in either the membrame or the vapour phase proper is determined partly by the liquid pressure $\pi_{1}{ }^{\prime}$ of the solvent inside the solution and partly by the work factor $\Lambda_{1}{ }^{\prime}$; so that we can regard the munitude and direction of osmotic flow as being caused ultinately by differences in the value of $\pi_{1}{ }^{\prime}$ and $A_{1}{ }^{\prime}$ for the two solutions. If the differences in the value of $A_{1}{ }^{\prime}$ are nil, the osmotic flow is thus determined entirely by the differences in $\pi_{1}^{3}$, the direction of the flow obviously proceeding from the solution in which the solvent has the higher fluid pressure to the one in which it has the Iower fluid pressure $\neq$. If, on the other hand, the differences in $\pi_{1}{ }^{\prime}$ are eliminated, as by working with dilute solutions of equal concentration on opposite sides of the membrane, the direction of flow is determined entirely by the differences in the value of $A_{1}^{\prime}, i$.e. (and as shown above) by the differences in heats of dilution, intrinsic pressure, surface-tension, \&c.

The problem can be resolved even still further. The pressure of the solvent inside a solution is itsolf determined by its molar fraction and also by the change in volume which it undergoes during the process of solntion (equation [2] 1. 432) ; so that in the general case we can state that the

* Cf. Macallum, Brit. Assoc. Reports, 1910, p. 740. It is clear also that in the case we have been considering the velocity of osmosis will be determined largely by intrinsic pressure (and surface-tension) differences between the two solutions. In this connexion it is interesting to note that Frof. Adrian Brown and the author have found that the rate of osmotic flow into barley seeds becomes greater as the surface-tension of the outside solution diminishes. (Proc. Roy. Soc. B. lxxxix. p. 119 (1915).)

+ I. e. partial pressure of the solvent.

+ Tinker, 'Nature,' xevii. p. 12j (1916). This idea of osmosis being deterinined by magnitude of the fluid pressure of the solvent seems to have been foreshadowed by Porter (Proc. Roy. Soc. A. Ixxx. p. 457 (1908), Addendum to paper). 
magnitude and direction of osmotic flow is ultimately determined, partly by the relative concentrations of the two solutions, partly by their relative heats of dilution, surfacetensions, intrinsic pressures, \&e., and partly by the relative magnitude of tho rolume changes which the solvent undergoes during the process of solution. If, on the ono hand, we eliminate surface-ten-ion and intrinsic pressure differences, \&c., by working with two ideal solutions on oppoite sides of the membrane, the direction of flow is invariably from the weaker solution to the stronger one. If, on the other hand, we eliminate concentration differences and work with two non-ideal dilute solutions of equal strength, the direction of flow is (as shown above) from the solution having the lower heat of dilution, surface-tension, intrinsic pressure, \&c., to that having the higher value of these quantities; in fnct, Trauhe's theory of osmosis holds good. Whilst if we eliminate both concentration and surface-tension differences, \&c., by working with two equally strong non-ideal solutions having equal heats of dilution, the direction of flow will be towarls the solution in which the solvent has undergone the greater expansion during the process of solution.

\section{The Conditions at Osmotic Equllimilum.}

Consider again the case in which pure solvont and solution are separated by a semi-perweable membrane which is thick enough to be regarded as a separate phase in the osmotic system* . Let the pure solvent be under the atmospheric pressure $a$, and the solution under such a hydrostatic pressure $\mathbf{P}$ that the solvent and solution are in osmotic equilibrium.

(a) Relationship belween the Pressure of the Solvent in the various parts of an Osmotic System, the latter being at Equilibrium.

It is evilent that, when a system is at osmotic equilibrium, the pressure $\left(\rho_{1}^{\prime}{ }_{(\mathrm{P})}\right)$ generated inside the membrane by the solution must be equal to the pressure $\left(\rho_{1(a)}\right)$ generated by the pure solvent, just as the vapour pressures proper of pure solvent and solution are equal at osmotic equilibrium $\dagger$.

* Footuiste (*) on p. 438.

† Thomson \& Poynting, 'I'roperties of Matter,' p. 121 . A. W. Pouter, Proc. Ruy. Soc. A. Ixxix. p. 519 (1907, ibid. A. lx xx.p. 457 (1908). 'The' ultimate proof of both the theore ms mentioned is very simple. If the pressure were not unifom $m$ in either the membrane or in the vapour phase proper. a proifss of diffusion would take place. The fact that work could be obtaine $d$ from the prucess can be made to contradict the second law of thermodynamics. 
Starting from inside the membrane, and travelling outwards into pure solvent and solution respectively through the surface film between the membrane and the liquid in each case, let us now apply the Dieterici equation in its simplest form.

For the pressure $\pi_{1_{(u)}}$ in:ide the pure solvent we have

$$
\pi_{1_{(u)}}=\rho_{1_{(a)}} e \frac{\mathrm{R}_{1}}{\mathrm{I}^{\mathrm{T}}}
$$

we have $\pi_{1(\mathbf{P})}^{\prime}$ of the solvent inside the solution

$$
\pi_{1}^{\prime}{ }_{(\mathrm{P})}=\rho_{1_{(\mathrm{P})}^{\prime}}^{\prime} e^{\mathrm{B}_{1}^{\prime} \mathrm{I}^{\prime} \cdot \mathrm{P}}
$$

where $B_{1}$ and $B_{1}{ }^{\prime}$ have a similar meaning to $A_{1}$ and $A_{1}$, referring, however, to evaporation into the membrane. Hence, since $\rho_{1}^{\prime}{ }_{(\mathbb{P})}=\rho_{1_{(a)}}$ (see above), we get

whence

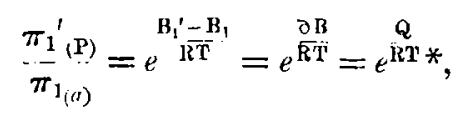

$$
\pi_{i_{\langle(\mathbb{P})}}^{\prime}=\pi_{1_{(a)}} e^{\frac{\mathrm{Q}}{\mathrm{RT}}}=\pi_{1_{(a)}}\left(1+\frac{\mathrm{Q}}{\mathrm{R}^{\top} \mathrm{T}}\right) \text { (approx.). }
$$

From this equation [17] it appears that, if the solution is an idtal one with zero heat of dilution, at osmotic equilibrium the pressure $\pi_{1}^{\prime}(\mathrm{P})$ of the solvent inside the solution is equal to the pressure $\pi_{1(a)}$ of the solvent inside the pure solvent. When therefore the solution bas no heat of dilution, we can lay down the fundamental generalization that at osmotic equilibrium the pressure of the solvent is uniform in similar phases throughout the whole osmotic system. The pressure of the solvent throughout the vapour phase is unitorm; it is also uniform throughout the membrane; whilst the pressure of the solvent inside the solution is equal to that inside the pure solvent. The generalization breaks down, however, in the case of non-ideal solutions. Although it is still true that the pressure within the membrane and in the vapour phase proper is uniform, the pressure inside the solution is not equal to that inside the pure solvent. It is greater or less than the latter according as the heat of dilution of the solution is positive or negative ( $f f$. equation [17]).

* Supra, p. 436. At osmotic equilibrium the relationship $\partial \mathrm{B}=\mathrm{Q}$ is absolutely accurate, for the clange in internal eneryy is zero whon there is no expansion. 
(b) The Magnitude of the Osmotic Pressure.

As is well known*, the application of hydrostatic pressure to a solution increases the vapour pressure of the latter, and when a pressure equal to the osmotic pressure is pat on the solution, the vapour pressures of the solvent and solution become equal to one another. We may therefore define the osmotic pressure as the hydrostatic pressure which, when applied to the solution, will raise the vapour pressure up to that of the pure solvent, and which incidentally will also bring the pressure generated inside the membrane by the solution up to that generated by the solvent. This definition is, of course, merely a slight extension of the usual definition that the osmotic pressure is the hydrostatic pressure which (when applied to the solution) stops the osmotic flow.

Taking the above definition as the basis, we can now arrive at the magnitude of the osmotic pressure very simply by making use of the relationship between the vapour pressure of a liquid and the hydrostatic pressure to which it is subjected which was first obtained by Sir J. J. Thomson for pure liquids $\dagger$ and extended by A. W. Porter to solutions in general $\ddagger$.

$$
\text { Porter's relationship is } \frac{d \Pi}{d p_{1}}=\frac{v}{s}, \ldots . . . \quad \text {. . }
$$

where $\Pi=$ hyclostatic pressure.

$$
\begin{aligned}
& p_{1}^{\prime}=\text { partial vapour pressure of solvent at pres- } \\
& \text { sure } \Pi \text {. } \\
& v=\text { sp. vol. of vapour at pressure } \Pi \text {. } \\
& s=\text { sp. vol. of the solvent in the solution at } \\
& \text { pressure } \Pi \text {. } \\
& \quad(i . e \text {. the loss in vol. when } 1 \mathrm{gm} \text {. solvent } \\
& \text { is removed from the solution.) }
\end{aligned}
$$

Multiplying both $v$ and $s$ by the molec. wgt., and assuming that the vapour obeys the simple gas law, we have

$$
\frac{d \mathrm{II}}{d p_{1}^{\prime}}=\frac{\mathrm{RT}}{p_{1}^{\prime} \mathrm{V}_{1}^{\prime}}
$$

where $V_{1}^{\prime}$ is the molec. vol. of the solvent in the solution under the hydrostatic pressure $\Pi$, whence

$$
d \Pi=\frac{\mathrm{RT}^{\prime} \mathrm{T}}{\overline{\mathrm{V}}_{1}^{\prime}} \cdot \frac{d p_{1}^{\prime}}{p_{1}{ }^{\prime}} .
$$

* Supra, also, p. 439.

+ 'Application of Dynamics to Physics and Chemistry,' p. 171.

\pm Proc. Koy. Soc. A. Ixxix. p. 519 (1907). 
Putting $V_{1}^{\prime}=V_{1_{(a)}}-\Pi \beta V_{1_{(a)}}$, where $\beta$ is the coefficient of compressibility of the solution and $V_{1_{(a)}^{\prime}}$ is the mol. vol. of the solvent at the atmos. press., we get

$$
d \Pi(1-\Pi \beta)=\frac{\mathrm{RT}}{\bar{V}_{1_{(\alpha)}^{\prime}}} \cdot \frac{d p^{\prime}}{p_{1}^{\prime}} .
$$

Integrating between the limits represented by the osmotic pressure $\mathrm{P}$ and zero hydrostatic pressure ${ }^{*}$, and remembering that $p_{1(\mathbf{P})}{ }^{\prime}=p_{1_{(\alpha)}}$, we obtain

whence

$$
\int_{0}^{\mathbf{P}} d \Pi-\beta \int_{0}^{\mathbf{P}} \Pi d \Pi=\frac{\mathrm{RT}}{V_{1_{(l)}^{\prime}}^{\prime}} \int_{p_{1^{\prime}(a)}^{p_{1}(a)}}^{p^{\prime}} \frac{d p_{1}^{\prime}}{p_{1}^{\prime}}
$$

$$
\mathrm{P}-\frac{1}{2} \beta \mathrm{P}^{2}=\frac{\mathrm{RT}}{\mathrm{V}_{1_{(a)}^{\prime}}^{\prime}} \log e \frac{p_{1_{(a)}}}{p_{1_{(a)}^{\prime}}^{\prime}} . . .
$$

This is the general equation connecting the osmotic pressure with the vapour pressure of the pure solvent and solution when both are at the atmospheric pressure. With the exception that $\nabla_{1}^{\prime}$ is written for $V_{1}$, it is identical with the equations given by Gibbs, Van Laar, and others. It holds for all solutions irrespective of association of the solvent, formation of solvates, \&c., or of abnormalities in latent heat, \&c.

Substituting the values of $\frac{p_{1}}{p_{1}}$ given in equation $[10]$, we get for the type of solutions we have been dealing with $\mathrm{P}-\frac{1}{2} \beta \mathrm{P}^{2}$

$$
\begin{aligned}
& =\frac{\mathrm{RT}}{\mathrm{V}_{1_{(a)}^{\prime}}^{\prime}} \log _{e}\left\{\frac{\mathrm{N}+n}{\mathrm{~N}}-\frac{n}{\mathrm{~N}}\left(1-\frac{\mathrm{V}_{2}-b_{2}+\epsilon_{(a)}}{\mathrm{V}_{1}-b_{1}^{-}}\right)\right\} e^{\frac{\mathrm{R} T}{\mathrm{RT}}} \\
& =\frac{\mathrm{RT}}{\mathrm{V}_{1_{(a)}^{\prime}}^{\prime}} \log _{e}\left\{\frac{\mathrm{N}+n}{\mathrm{~N}}-\frac{n}{\mathrm{~N}}\left(1-\frac{\mathrm{V}_{2}-b_{2}+\epsilon_{(a)}}{\mathrm{V}_{1}-b_{1}}\right)\right\}+\frac{\mathrm{R}^{\prime} \mathrm{T}}{\mathrm{V}_{1_{(a)}^{\prime}}^{\prime}} \log _{e} \frac{\mathrm{Q}}{\mathrm{R}^{\prime} \mathrm{T}}, \\
& =\frac{\mathrm{R}^{\prime} \mathrm{T}}{\mathrm{V}_{1_{(a)}^{\prime}}^{\prime}} \log _{e}\left\{\frac{\mathrm{N}+n}{\mathrm{~N}}-\frac{n}{\mathrm{~N}}\left(1-\frac{\mathrm{V}_{2}-b_{2}+\epsilon_{(a)}}{\mathrm{V}_{1}-b_{1}}\right)\right\}+\frac{\mathrm{Q}}{\mathrm{V}_{1_{(a)}^{\prime}}^{\prime}} \text {. }
\end{aligned}
$$

When the solution is dilute we have $V_{1}^{\prime}=V_{1}$ (see $p^{4} 433$ ); the compressibility factor becomes negligible; the expression in brackets becomes equal $\frac{N+n}{N}$ (pp. 433, 434); $\log _{e} \frac{\mathrm{N}+n}{\mathrm{~N}}=\frac{n}{\mathrm{~N}}$ approx.; so that the expression reduces to

$$
\mathrm{PV}_{1}=\mathrm{RT} \frac{n}{\mathrm{~N}}+\mathrm{Q} \cdot \cdot \cdot \cdot .
$$

* I. e. zero mechanical hydrostatic pressure, not counting the atmo. spheric pressure.

Phil. Mag. S. 6. Vol. 33. No. 197. May 1917. $2 \mathrm{H}$ 
If instead of writing $\mathrm{V}_{1}$ (i.e. the mol. vol. of the liquid solvent) we write $V$ (the volume of solution containing 1 gm. mol. of solute $=\frac{\mathrm{N}}{n} \mathrm{~V}_{1}$ ), and $q$ for $\frac{n}{\mathrm{~N}} \mathrm{Q}$, we get

$$
\mathrm{PV}=\mathrm{RT}+q \cdot \cdot \cdot \cdot \cdot \cdot
$$

This is the simple gas equation corrected for the heat of dilution which has already been given by Bancroft*. In this connexion it is to be noted that the osmotic pressure of a dilute solution is given by the simple gas equation only when the solution has zero heat of dilution. If the heat of dilution is positive the osmotic pressure is abnormally higb, whilst if it is negative the osmotic pressure is abnormally low. Bancroft, for instance, has shown that dilute solutions of sulphuric acid in water. sodium in mercury, and resorcinol in alcohol have osmotic pressures which are several times as great as would be given by the gas law ; whilst Kahlenberg $\dagger$ ha; demonstrated t! iat solutions of cane-sugar, lithinm chloride, and certain other solutes in pyridine give osmotic pressures which are only a fraction of what the simple gas law would require them to be.

It is apparent also from the method of deriving the preceding equation [22] that the abnormalities in the osmotic pressure of dilute solutions have their origin in abnormalities in the vapour pressure, and hence ultimately in the difference in the in trinsic pressures of the solvent and solution. Traube's surface-tension theory is therefore of value in predicting abnormalities in the osmotic pressure also. As a general rule, if the surface-tension of a solution is low the osmotic pressure would also tend to be low; and vice versa. Hence, in many cases, the apparent flow of the solvent from the region of low surface-tension to high (supra, p. 440).

\section{(C) Compressibility Relationships at Usmotic Equilibrium.}

It has heen pointed out previously that the application of hydrostatic pressure to the solution causes both $\pi_{1}^{\prime}, p_{1}^{\prime}$, and $\rho_{1}{ }^{\prime}$ to increase, owing to the fact that compression reduces $n \epsilon$ and brings the molecules inside the solution more closely together. We can obtain the contraction at osmotic equilibrium as follows :-

The general equation connecting $\pi_{1}$ and $\pi_{1}^{\prime}$ is [5], viz.

$$
\begin{aligned}
& \frac{\pi_{1}}{\pi_{1}^{\prime}}=\left\{\frac{\mathrm{N}+n}{\mathrm{~N}}-\frac{n}{\mathrm{~N}}\left(1-\frac{\mathrm{V}_{2}-b_{2}+\epsilon}{\mathrm{V}_{1}-b_{1}}\right)\right\} . \\
& \quad \text { * Journ. Phys. Chem. x. p. } 322(1906) . \\
& \quad+\text { Ibid. x. p. } 141 \text { (1906). }
\end{aligned}
$$


But at osmotic equilibrium,

(see p. 443).

$$
\frac{\pi_{1}}{\pi_{1}^{\prime}}=e^{-\frac{\mathrm{Q}}{\mathrm{RT}}}=1-\frac{\mathrm{Q}}{\mathrm{RT}}
$$

Hence, if $\epsilon_{(P)}$ is the total expansion per solute molecule when the solution is under the hydrostatic pressure $\mathrm{P}^{*}$ (i.e. the osmotic pressure), we have

whence

$$
\frac{\mathrm{N}+n}{\mathrm{~N}}-\frac{n}{\mathrm{~N}}\left(1-\frac{\mathrm{V}_{2}-b_{2}+\epsilon_{(\mathrm{P})}}{\mathrm{V}_{1}-b_{1}}\right)=1-\frac{\mathrm{Q}}{\mathrm{RT}}
$$

$$
n \varepsilon_{(\mathbf{P})}=-n\left(\mathrm{~V}_{2}-b_{2}\right)-\frac{\mathrm{N}\left(\mathrm{V}_{1}-b_{1}\right) \mathrm{Q}}{\mathrm{RT}} \ldots . .
$$

Now the contraction due to applying the osmotic pressure to the solution is $n \epsilon_{(\alpha)}-n \epsilon_{(P)}$; and if $\beta$ is the average coefficient of compressibility of the solution $\dagger$ between zero pressure and the osmotic pressure, it is also equal to $\mathrm{P} \beta\left(\mathrm{NV}_{1}^{\prime}+n \mathrm{~V}_{8}^{\prime}\right)$.

Hence

$$
\mathrm{P} \beta\left(\mathrm{NV}_{1}^{\prime}+n \mathrm{~V}_{2}^{\prime}\right)=n \epsilon_{(\alpha)}-n \epsilon_{(\mathrm{P})}, . .
$$

where $\epsilon_{(a)}$ and $\epsilon_{(P)}$ have the values given to them by equations [7] and [23] respectively.

For dilute solutions with no beat of dilution, we can neglect $n V_{2}^{\prime}$; and substituting the values of $\epsilon_{(a)}$ and $\epsilon_{(P)}$ for such solutions, the equation becomes

$$
\begin{aligned}
\mathrm{P} \beta N \mathrm{~V}_{1} & =n\left\{\left(\mathrm{\nabla}_{1}-b_{1}\right)-\left(\mathrm{V}_{2}-b_{2}\right)\right\}-\left\{-n\left(\mathrm{~V}_{2}-b_{2}\right)\right\} \\
& =n\left(\mathrm{~V}_{1}-b_{1}\right) .
\end{aligned}
$$

Putting

this becomes

$$
\mathrm{PV}_{\mathrm{i}}=\mathrm{RT} \frac{n}{\mathrm{~N}}
$$

whence

$$
\begin{aligned}
\mathrm{RT}_{\overline{\mathrm{N}}}^{n} \cdot \mathrm{N} \beta & =n\left(\mathrm{~V}_{1}-b_{1}\right) ; \\
\beta & =\frac{\mathrm{V}_{1}-b_{1}}{\mathrm{RT}}
\end{aligned}
$$

and

$$
\mathrm{V}_{1}-b_{1}=\beta \mathrm{RT} \ddagger \text {. . . . . }
$$

- Supra, p. 432. The value of $\epsilon$ varies with the hydrostatic pressure placed on the solution, diminishing with increase of the latter and tending to become more and more negative with high pressures.

+ Defined as the shrinkage of 1 c.c. per atmosphere applied.

$I$ It is to be remembered that, since $P$ is mensured in atmospheres and $V$ in c.c., the constant $R$ is moasured in c.c. atmospheres and is equal to $82 \cdot 07$. 
or in words, the free space within a dilute solution having no heat of dilution is equal to R'T times the coefficient of compressibility. This relationship is important, for it enables the "free space" within a dilute solution to be calculated very easily. Since the pure solvent is the limiting case of a dilute solution, and has perforce no heat of dilution, it will be seen that the above relationship should hold absolutely for pure liquids. It is to be noted, however, that the coefficient of compressibility must be taken at atmospheric pressure and not at relatively high pressures *.

We can now use equation [25] for obtaining the general equation for the osmotic pressure in terms of the concentrations, volume change on solution, and the coefficients of compressibility $\beta_{1}, \beta_{2}$, and $\beta$ for the pure solvent, pure solute, and solution respectively.

From equation [20], viz.

$$
\begin{aligned}
\mathrm{PV}_{1_{(a)}^{\prime}}(1 & \left.-\frac{1}{2} \beta \mathrm{P}\right) \\
= & \mathrm{RT} \log _{s}\left\{\frac{\mathrm{N}+n}{\mathrm{~N}}-\frac{n}{\mathrm{~N}}\left(1-\frac{\mathrm{V}_{2}-b_{2}+\epsilon_{(a)}}{\mathrm{V}_{1}-b_{1}}\right)\right\}+\mathrm{Q},
\end{aligned}
$$

by substituting

$$
\begin{aligned}
& \left(\mathrm{V}_{1}-b_{1}\right)=\beta_{1} \mathrm{RT}, \quad \mathrm{V}_{2}-b_{2}=\beta_{2} \mathrm{RT}, \\
& \text { and } \mathrm{V}_{1_{(a)}^{\prime}}^{\prime}=\mathrm{V}_{1_{(a)}}-\frac{n}{\mathrm{~N}+n}\left\{\left(\mathrm{~V}_{1}-b_{1}\right)-\left(\mathrm{V}_{2}-b_{2}+\epsilon_{a}\right)\right\} \\
& \text { we get } \quad \text { (cf. equation [7]), } \\
& \begin{array}{r}
\mathrm{P}\left\{\mathrm{V}_{1(a)}-\frac{n \mathrm{RT}}{\mathrm{N}+n}\left(\beta_{1}-\beta_{2}-\frac{\epsilon}{\mathrm{RT}}\right)\right\}\left\{1-\frac{1}{2} \beta \mathrm{P}\right\} \\
=\operatorname{RT} \log _{e}\left\{\frac{\mathrm{N}+n}{\mathrm{~N}^{-}}-\frac{n}{\mathrm{~N}}\left(\frac{\left.\beta_{1}-\beta_{2}+\frac{\epsilon_{(a)}}{\mathrm{RT}}\right)}{\beta_{1}}\right)\right\}+\mathrm{Q} .
\end{array}
\end{aligned}
$$

$\beta_{1}$ and $\beta_{2}$ are both usually very small, so that we can count $\beta_{1}-\beta_{2}$ as zero without appreciable error.

The equation then becomes

$$
\begin{aligned}
\mathrm{P}\left(\mathrm{V}_{1}+\frac{n \epsilon_{(a)}}{\mathrm{N}+n}\right) & \left(1-\frac{1}{2} \beta \mathrm{P}\right) \\
= & \mathrm{RT} \log _{e}\left\{\frac{\mathrm{N}+n}{\mathrm{~N}}-\frac{n \varepsilon_{(a)}}{\mathrm{N} \beta_{1} \mathrm{RT}}\right\}+\mathrm{Q} .
\end{aligned}
$$

It is clear also that with all but the strongest solutions we

* As is well known, the coefficient of compressibility varies considerably with the pressure. 
can neglect $\frac{n \varepsilon_{(\alpha)}}{\mathrm{N}+n}, \frac{n \varepsilon_{(a)}}{\mathrm{N} \beta_{1} \mathrm{RT}}$, and also $\frac{1}{2} \beta \mathrm{P}$; so that we have, for most moderately strong solutions,

$$
\mathrm{PV}_{1}=\mathrm{RT} \log _{e} \frac{\mathrm{N}+n}{\mathrm{~N}}+\mathrm{Q} \text {. }
$$

This equation is similar to that Van Laar and others have given for the ideal solution, except that the heat of dilution is included.

A part from the fact that the method of analysis adopted in the preceding pages throws much light on the anomalies of osmotic pressure and osmotic flow, still further confirmation of its intrinsic soundness becomes apparent when we consider in detail the fundamental relationship which has been deduced between the coefficient of compressibility of a liquid and its free space.

The following table shows the value of $(\mathrm{V}-b)$ for various liquids, calculated from equation [20] by means of compressibility data given in Landolt-Bornstein. The value of the pressure inside the liquid is also given, being calculated from the relationship $\pi \beta=1 *$.

\begin{tabular}{|c|c|c|c|c|c|c|c|}
\hline Liquid. & $\begin{array}{c}\text { Temp. } \\
\text { oc. }\end{array}$ & \multicolumn{4}{|c|}{$\begin{array}{c}\text { Compressibility, } \\
\beta \times 10^{6}\end{array}$} & $\begin{array}{l}(v-b) \text {, } \\
\text { in c.c. }\end{array}$ & $\begin{array}{c}\pi \\
\text { in atmos. }\end{array}$ \\
\hline Ether ............... & 13.5 & 169 & fror & $8-25$ & (mos.) & $3 \cdot 97$ & 5920 \\
\hline Ethyi Ohloride.. & $15 \cdot 2$ & 153 & , & $8-34$ & ", & $3 \cdot 60$ & 6550 \\
\hline Ethylene $\ldots . . . .$. & $10 \cdot 0$ & 68 & & - & & $1 \cdot 58$ & 14700 \\
\hline Ethyl Acetate . & $13: 3$ & 104 & " & 8-37 & $"$ & $2 \cdot 44$ & 9600 \\
\hline Benzene ........ & 160 & 80 & , & $8-37$ & " & $2 \cdot 13$ & 11100 \\
\hline Amylene...... & $13 \cdot 0$ & 172 & " & $8-37$ & , & $4 \cdot 05$ & 5810 \\
\hline Pentane.... & $20 \cdot 0$ & 318 & & - & & $7 \cdot 63$ & 3150 \\
\hline Herane ...... & $23 \cdot 0$ & 159 & ", & $0-1$ & $n$ & $3 \cdot 85$ & 6290 \\
\hline Heptane............ & $23 \cdot 0$ & 134 & , & $0-1$ & " & $3 \cdot 25$ & 7460 \\
\hline Octane ............ & $23 \cdot 0$ & 121 & ,, & $0-1$ & " & $2 \cdot 94$ & 8270 \\
\hline
\end{tabular}

The subjoined table gives the figures for ethyl ether at various temperatures also, Amagat's compressibility data boing used $t$.

The intrinsic pressures calculated from the relationship in question are evidently of the usually accepted order of

* This simple relationship follows immediately from the two relations $\beta=\frac{\mathrm{V}-b}{\mathrm{RT}}$ and $\pi=\frac{\mathrm{RT}}{\mathrm{V}-\mathrm{b}}$.

† Ann. Chim. Phys. (6) xxix. p. 505 (1893). 


\begin{tabular}{|c|c|c|c|}
\hline $\begin{array}{c}\text { T'omp. } \\
\circ \mathrm{C} .\end{array}$ & $\begin{array}{c}\text { Compressibilty, } \\
\beta \times 106, \\
\text { at from } 50-100 \text { atmos. }\end{array}$ & $\begin{array}{c}(\nabla-b), \\
\text { in c.c. }\end{array}$ & $\begin{array}{c}\pi, \\
\text { in atmos. }\end{array}$ \\
\hline 0 & 133 & $2 \cdot 98$ & 7520 \\
20 & 158 & $3 \cdot 79$ & 6400 \\
40 & 203 & $5 \cdot 25$ & 4940 \\
60 & 252 & $6 \cdot 89$ & 3970 \\
80 & 315 & $9 \cdot 13$ & 3180 \\
100 & 395 & $12 \cdot 00$ & 2540 \\
\hline
\end{tabular}

magnitude of a few thousand atmospheres; whilst, as should also be the case, the values for the free space are relatively small as compared with the volumes of the molecules themselves.

XLII. Studies of the Ultra-violet Transparency of Certain Coloured Media. By II. W. L. Absalom, B.Sc., A.R.C.S." $7 \mathrm{IHE}$ present investigation originated in an attempt to 1 find some colouring matter which, while opaque in the yellow region of the spectrum, should transmit as far as possible into the ultra-violet. Such a material would be of great use in developing certain investigations on the fluorescence of sodium vapour which have been made in this laboratory (see Strutt, Proc. Roy. Soc. Nov. 1915).

With this object a number of little-known colouring matters were examined, and the subject was afterwards pursued for points of interest it was found to possess in itself.

The coloured metallic salts and the aniline dyes have already been well explored (see Uhler and Wood, "Atlas of Absorption Spectra'), but fow of them possess much altraviolet trausparency. Attention was turned therefore to the blue rock-salt of Stassfurt, believed to owe its colour to colloidal sodium. This was found to be very transparent, and the observation led on to investigation of other naturally coloured minerals and precious stones as well as to various preparations of colloidal metals, such as the solutions of alkali motals in anhydrous liquid ammonia.

\section{Gems and Minerals.}

The arc between copper poles was employed as the source of radiation. By means of a small quartz spectrograph, photographs were obtained of the portion of the spectrum between $\lambda 5000$ and $\lambda 2250$. The specimen under exami-

- Communicated by the Author. 